\title{
$1 \quad$ Nutrition in early life and age-associated diseases
}

2

3 Jane L Tarry-Adkins ${ }^{\mathrm{a}}$, Susan E Ozanne ${ }^{\mathrm{a}}$

$4{ }^{\mathrm{a}}$ University of Cambridge Metabolic Research Laboratories and MRC Metabolic Diseases

5 Unit, Institute of Metabolic Science, Level 4, Box 289, Addenbrooke's Treatment Centre,

6 Addenbrooke's Hospital, Hills Road, Cambridge, CB2 OQQ, UK.

7

8 Corresponding author: Jane L Tarry-Adkins

9 Corresponding author at: University of Cambridge Metabolic Research Laboratories and 10 MRC Metabolic Diseases Unit, Institute of Metabolic Science, Level 4, Box 289,

11 Addenbrooke's Treatment Centre, Addenbrooke's Hospital, Hills Road, Cambridge, CB2 12 OQQ, UK.

13

14 Email addresses: janeadkins@googlemail.com, seo10@cam.ac.uk 


\section{Abstract}

The prevalence of age-associated disease is increasing at a striking rate globally. It is known that a strong association exists between a suboptimal maternal and/or early-life environment and increased propensity of developing age-associated disease, including cardiovascular disease (CVD), type-2 diabetes (T2D) and obesity. The dissection of underlying molecular mechanisms to explain this phenomenon, which is known as 'developmental programming' is still emerging; however three common mechanisms have emerged in many models of developmental programming. These mechanisms are a) changes in tissue structure, b) epigenetic regulation and c) accelerated cellular ageing. This review will examine the epidemiological evidence and the animal models of suboptimal maternal environments, focusing upon these molecular mechanisms and will discuss the progress being made in the development of safe and effective intervention strategies which ultimately could target those 'programmed' individuals who are known to be at-risk of age-associated disease.

Key Words: Developmental programming, mechanism, sub-optimal nutrition, ageassociated disease, oxidative stress. 
Organismal ageing can be defined as an age-dependent or age-progressive decline in physiological function, leading to an increase in age-specific mortality rate and a decrease in age-specific reproductive rate. With the number of people aged 65 or over estimated to increase from 524 million in 2010 to 1.5 billion in 2050, the prevalence of age-associated diseases (including cardiovascular disease (CVD), glucose intolerance, insulin resistance, type-2 diabetes (T2D), non-alcoholic fatty liver disease (NAFLD), cancer, dementia and obesity) is increasing at an astonishing rate globally. Consequently; this has major implications on worldwide mortality causes, with age-associated diseases making up more than $60 \%$ of all deaths worldwide. These sobering statistics can be explained to a certain degree by increases in global longevity, which has partially been caused by shift in causes of mortality; (from infectious and parasitic diseases, to non-communicable diseases), however it is clear that other mechanisms are also important.

\section{The concept of developmental programming - Epidemiological evidence}

Twenty five years ago, Hales and Barker published seminal papers which described strong associations between suboptimal growth in early life and increased risk of impaired glucose tolerance (Hales et al., 1991), T2D (Hales and Barker, 1992) and metabolic syndrome and CVD (Barker et al., 1993) in later life. Hales and Barker named this phenomenon The Thrifty Phenotype Hypothesis, which suggests that in a poor in-utero milieu, the fetus permanently alters its organ structure and adapts its metabolism to ensure immediate survival of the organism. This can occur through the 'sparing' of certain vital organs, especially the brain, at the expense of other organs, including the heart, pancreas, liver, kidney and skeletal muscle, a phenomenon known as 'developmental programming' (Figure 1). A common phenotype in these offspring is in-utero growth restriction (IUGR). 


\subsection{Maternal under-nutrition (in-utero growth restriction)}

These seminal studies have been reproduced in many epidemiological populations throughout the world (reviewed by Hales and Barker, 2001). One of the most compelling pieces of epidemiological evidence for the Thrifty Phenotype Hypothesis came from the Dutch Hunger Winter. Between late November 1944 and early May 1945, people who were previously well-nourished, experienced a very severe famine due to food blockades during World War II. A study by Ravelli and colleagues showed that offspring of mothers who were pregnant during the famine had a low birth-weight and were glucose intolerant in later life (Ravelli et al., 1998). It has also been shown that the time window of exposure to the famine is important: Increased prevalence of coronary heart disease, a raised atherogenic lipid profile and increased adiposity were observed in offspring of mothers exposed to famine in early gestation (Roseboom et al., 2006), whereas those offspring whose mothers were exposed to famine during mid gestation had increased microalbuminurea and deteriorated renal function in adulthood (Painter et al., 2005), whereas those exposed in late gestation had the greatest risk of T2D (Ravelli et al., 1998).

The idea that risk of T2D, CVD and the metabolic syndrome may be altered by the environment per-se and not genetic determinants has been supported by studies in monozygotic twins, in which the twin with the lower birth weight developed T2D (Poulsen et al., 1997), glucose intolerance (Grunnet et al., 2007) and impaired insulin secretion and insulin resistance in later life (Poulsen et al., 2002, Poulsen and Vaag, 2006), compared to the genetically identical twin with a normal birth weight. Importantly, the latter studies revealed that these associations occur in an age-dependent manner, which may part; explain the highly age-dependent states of T2D, CVD and the metabolic syndrome.

\subsection{Maternal over-nutrition (maternal obesity and gestational diabetes)}



proportions, the issue of maternal obesity is becoming increasingly important. Obese women have increased risk of having large for gestational age and small for gestational age offspring (Djelanik et al., 2011). Maternal obesity (which is associated with gestational diabetes) can cause macrosomic offspring, rather than IUGR as gestational diabetes results in maternal hyperglycaemia. As glucose can cross the placental barrier but maternal insulin cannot, the fetus attempts to regulate its own glucose homeostasis by increasing insulin production from fetal $\beta$-cells of pancreatic islets. As insulin is a potent growth factor in fetal life, this can result in macrosomic offspring. The deleterious effects of maternal hyperglycaemia in the offspring are well known. In Pima Indians, a population with high levels of gestational diabetes and T2D (who also have a very high prevalence of obesity), the association of birth weight with T2D has been shown to be U-shaped, with the highest prevalence of T2D and obesity present in both low and high birth weight offspring (McCance et al., 1994). In the general population, it has been shown that children who are large for gestational age at birth and exposed to an intrauterine environment of either diabetes or maternal obesity are at increased risk of developing the metabolic syndrome (Boney et al., 2005) and children from obese mothers are more prone to overweight/obesity, central adiposity and greater fat mass in later life, independent of confounding factors (Daraki et al., 2015, Whittaker, 2004). Maternal obesity during pregnancy has also been linked to increased risk of premature mortality from CVD events (Reynolds et al, 2013) and to coronary heart disease risk (Gaillard, 2015) in the offspring.

\subsection{Postnatal catch-up growth}

It is evident that the fetal environment is an important determinant in the future prevalence of age-associated disease, including CVD and T2D; however the rate in which an individual grows postnatally is also known to have an impact on age-associated disease risk. 
This so-called 'mismatch' between a poor maternal environment followed by an adequate or over-sufficient postnatal environment (as evidenced by accelerated postnatal weight gain) has been linked to increased risk of many age-associated diseases including poor glucose tolerance (Crowther et al., 1998), insulin resistance (Ong et al., 2004), endothelial dysfunction (Touwslager et al., 2015), hypertension (Law et al., 2002), CVD (Erikkson et al., 2001) and NAFLD (Faienza et al., 2013) in many human cohorts. Conversely, it has been shown that breast feeding compared to formula feeding can induce slower postnatal growth (Fewtrell et al., 2001) and in large population-based studies, breast fed infants had reduced blood pressure (Martin et al., 2005), reduced risk of childhood obesity (Arenz et al., 2004), reduced cholesterol (Owen et al., 2002) and reduced insulin resistance (Ravelli et al., 2000) compared to those who were formula fed, independent of potential confounding factors.

\subsection{Animal Models}

Although we have gained some understanding of the concept of developmental programming from epidemiological studies, the underlying mechanisms and potential intervention strategies are impossible to elucidate without the use of animal models. Human studies have many confounding factors and the extensive lifespan make life course studies challenging. The shorter lifespan of most commonly used animal models (rodents) means that studies most relevant for understanding the aetiology of age-associated disease can more easily be attained. Therefore this review will now mainly focus on animal models of suboptimal nutrition in early life and what they have told us about programming of ageassociated disease.

\subsubsection{Maternal Protein Restriction}

As the Thrifty Phenotype Hypothesis suggests a key role for the supply of proteins and amino acids in fetal growth, maternal protein restriction has become one of the most 
commonly studied models of sub-optimal maternal nutrition. Initial studies in rats utilised an $8 \%$ low-protein (LP) diet, compared to a 'normal' $20 \%$ protein diet. These studies demonstrated that protein-restricted rat offspring were growth-restricted and underwent an age-dependent loss of glucose-tolerance, so that by 15 months of age, male LP offspring were frankly diabetic which was associated with insulin resistance (Petry et al., 2001). LP rat offspring also demonstrated perturbations in key molecules of the insulin signalling cascade (PKC- $\zeta$, GLUT-4 and $\mathrm{p} 85-\alpha$ ) in skeletal muscle, which occurred before the diabetic phenotype arose (Ozanne et al., 2005). Most importantly, these molecules were also downfostered offspring, termed 'recuperated' had reduced longevity compared to their control littermates in both rats (Jennings et al., 1999) and mice (Ozanne et al., 2004) and a postnatal 161 obesogenic diet in mice exacerbated the shortened lifespan in 'recuperated' offspring 
(Ozanne et al., 2004). Propensity to develop age-associated diseases has also been implicated in this model. In mice, an age-dependent development of fatty liver was observed in 'recuperated' offspring, which was associated with increased expression of genes implicated in lipid accumulation (Carr et al., 2014). Additionally, adipose tissue insulin resistance (Tarry-Adkins et al., 2015) and hepatic fibrosis and inflammation were observed in rat offspring of this model (Tarry-Adkins et al., 2016).

Conversely, we have also demonstrated that rodent offspring born to mothers fed a 'normal' (20\%) protein diet, and then suckled by mothers fed the low-protein (8\%) diet until weaning, underwent slow postnatal growth and demonstrated increased longevity in both rats (Jennings et al., 1999) and mice (Ozanne et al., 2004), compared to animals fed a control (20\%) protein diet during both gestation and lactation. The mice were also protected against shortened lifespan when challenged with an obesogenic diet after weaning (Ozanne et al., 2004). Phenotypically, reduced postnatal growth in mice increased thymic growth (an indication of reduced thymic ageing and consequently a marker of immunoprotection) (Chen et al., 2010), reduced splenic ageing (Heppolette et al., 2016), improved insulin sensitivity (Chen et al., 2009) and in rats, increased nephroprotection (Tarry-Adkins et al., 2007). Taken together, this suggests that slow postnatal growth is beneficial to the future health of offspring (a phenotype seen in breast-fed infants) and that a mild stress during early life is beneficial to lifespan maintenance. This supports the 'Hormesis hypothesis' which suggests that exposure of a mild stress (which in greater proportions would be detrimental) can improve the functional ability of organisms. This hypothesis has been successfully tested in many species as diverse as yeast, flies, worms and rodents, where a mild stress such a caloric restriction has been shown to increase longevity (LeBourg, 2009). Other hypotheses also exist to explain the effects of post-natal dietary restriction on health and longevity. The 
associated diseases are driven by processes that contribute to early-life fitness through growth and reproduction and then continue in later life at too high a level. It has been postulated that inhibiting or reducing this overload can help prevent aging/increase longevity (Blagosklonny 2007). It is thought that the nutrient sensing network, including growth hormone, IGF1 and TOR are implicit in promoting these activities (Fontana et al., 2010).

\subsubsection{Uteroplacental Insufficiency}

Uteroplacental insufficiency, a condition whereby the fetus is not gaining sufficient nutrients from its mother, is a common cause of IUGR in human pregnancies. Simmons and colleagues have developed an elegant rat model of uteroplacental insufficiency using bilateral uterine artery ligation. They demonstrated that rat dams that underwent this surgery had offspring which were growth restricted, had hepatic insulin resistance in young adult life (Vuguin et al., 2004), developed T2D in later life (Simmons et al., 2001) and had reduced glomerular number which was associated with increased apoptosis (Pham et al., 2003). Female rat offspring of mothers that underwent bilateral uterine artery ligation had selective uterine artery endothelial dysfunction and increased arterial stiffness (Mazzuca et al., 2010) and modest renal insufficiency (Moritz et al., 2009). Conversely, another group, using the same method to induce uteroplacental insufficiency, found that 12 month female offspring were hypertensive; however no evidence of glucose intolerance was observed (Tran et al., 2015).

\subsubsection{Maternal caloric/nutrient restriction}

Maternal food (nutrient/caloric) restriction is an important issue in developing countries, and consequently several animal models have been utilised to dissect underlying molecular mechanisms of this form of IUGR. Garafano et al. (1999) used a rat model of severe caloric restriction (50\% ad-libitum) and found that offspring of food restricted dams 
had an accelerated age-dependent loss of glucose tolerance. Others have utilised the same severity of maternal caloric restriction and showed that rat offspring were hypertensive with endothelial dysfunction (Franco et al., 2002) and had differential expression of genes associated with renal hypertension (Tain et al., 2015). In a non-human primate model of maternal nutrient restriction ( $70 \%$ of control food consumption), alterations in the renal transcriptome and kidney morphology was observed in offspring of nutrient restricted mothers (Cox et al., 2006). In an ovine model of $40 \%$ caloric restriction, combined with postnatal catch-up growth (which was induced by singleton compared to twin rearing), offspring were growth-restricted and then became obese, had insulin and leptin resistance and raised cortisol, a phenotype which was more severe than following in-utero caloric restriction alone (Dallschaft et al., 2014). In addition, hyperinsulinaemia, hyperleptinaemia and compensatory leptin production in pancreatic $\beta$-cells was observed in a rat model of $30 \%$ caloric restriction. This phenotype was also worsened when these offspring were exposed to hypercaloric nutrition after weaning (Vickers et al., 2001). This exacerbation of phenotype after accelerated postnatal growth is a common mechanism shared in models of maternal protein restriction and caloric restriction. Interestingly, caloric restriction can also ameliorate several hallmarks of cellular ageing including epigenetic alterations, stem cell depletion, cellular senescence, mitochondrial dysfunction, genomic instability (DNA repair mechanisms), proteostasis imbalance and impaired nutrient sensing (Michan et al., 2014).

\subsubsection{Maternal Iron Restriction}

Iron deficiency (anaemia) is the most common form of nutrient deficiency worldwide, affecting nearly 2 billion people and up to $50 \%$ of pregnant women and is a major cause of IUGR. Large placental weights and a high ratio of placental weight to birth weight (known predictors of adult blood pressure) have been observed in offspring of iron-restricted mothers (Godfrey et al., 1991), which may be due to alterations of placental cytokine expression, 
which can be regulators of growth and development (Gambling et al., 2002). Three monthold rat offspring of iron restricted mothers have reduced weight at birth which persisted until 3 months of age and had increased blood pressure (Lewis et al., 2001). The hypertensive phenotype has also been shown to be present until 16 months of age (Lisle et al., 2003).

\subsubsection{Maternal Obesity}

Animal models of maternal obesity are known to cause a range of age-associated disease pathologies in the offspring. Using a diet rich in simple sugars and saturated fat, male rat offspring born to obese dams have similar body weights between birth and 8 weeks of age, however at 8 weeks of age these offspring had increased biomass in the form of cardiac hypertrophy which was associated with hyperinsulinemia and increased phosphorylation of AKT, ERK, and mTOR activation (Fernandez-Twinn et al., 2012) and cardiovascular dysfunction (Blackmore et al., 2014). It is known that increases in biomass (namely hypertrophy and hyperphagia) underpin many age-associated diseases including CVD and T2D. The observed phenotypes are independent of the offspring's current body weight. This indicates that the observed phenotypes are driven by developmental programming per-se and not by differences in offspring weight gain. Female mouse offspring from obese mothers using the same obesogenic diet became hyperphagic between 4 to 6 weeks of age, and developed increased adiposity at 6 months of age which may further exaggerate the programmed metabolic and cardiovascular dysfunction (Samuelsson et al., 2007). Using the same murine model, offspring of obese mothers also develop a fatty liver phenotype which was associated with disrupted lipid metabolism (Alfaradhi et al., 2014), insulin resistance and dysregulation of metabolism (Oben et al., 2010). Hepatic lipotoxicity was also observed in offspring of primates fed an obesogenic diet (McCurdy et al., 2009). A 'junk food' diet 
259 (Bayol et al., 2010) also programs a fatty liver phenotype in rats which was also associated with disrupted lipid metabolism.

261

\subsubsection{Reproductive ageing}

The female reproductive system is more susceptible to age-associated functional decline compared to normal somatic ageing, due to menopause (estropause in animals) occurring far earlier than whole body ageing. Epidemiological evidence exists to suggest that female reproductive function can be influenced by the early environment, including timing of menarche (Slobada et al., 2007), fertility (De Bruin et al., 1998) and menopause (Elias et al., 2003). Recently, we have demonstrated an accelerated ageing phenotype, which was associated with decreased ovarian reserve and DNA damage in ovarian and oviduct tissues from maternally protein restricted rats (Aiken et al., 2013) and mice (Aiken et al., 2016) that underwent accelerated postnatal growth. This phenotype has been confirmed by others in rats (Guzman et al., 2014). Zambrano et al. (2005) have demonstrated that maternal protein restriction can also deleteriously affect the male reproductive system, with testicular weight, fertility rate and sperm count decreased in these offspring. Taken together, these findings suggest that reproductive ageing as well as traditional somatic ageing is also susceptible to the effects of 'developmental programming', potentially having implications for future generations.

\subsubsection{Trans-generational studies}

Recently, several studies have shown that the deleterious effects of suboptimal maternal environments do not merely have a direct effect on the long-term health outcomes of the first generation. It now seems evident that these phenotypes can be transmitted throughout the generations, in the absence of further insult. Offspring of mothers who were exposed to the Dutch Hunger Winter famine in-utero had increased adiposity and poor health 
283 (Painter et al., 2008) and children whose grandmothers participated in Ramadan fasting 284 during pregnancy were lighter and had lower placental weights (Alwasel et al., 2013).

285 Epidemiological evidence also suggests that paternal lineage is an important determinant in transgenerational transmission of a programming phenotype. Second generation (F2) offspring whose fathers were exposed to the Dutch Hunger Winter famine had a higher BMI compared to unexposed offspring (Veenendaal et al., 2013). In mice, metabolic changes observed in the offspring of mothers fed a high-fat diet were present in 3 generations after high-fed diet administration (Masuyama et al., 2015) and offspring of mice undernourished in-utero had perturbed metabolic profiles which was maintained for 50 generations (Hardikar et al., 2015). In rats, maternal protein restriction followed by accelerated catch-up growth decreased ovarian reserve, increased intra-abdominal fat mass and accelerated ovarian ageing in the second generation (Aiken et al., 2015).

\subsection{Common underlying mechanisms of developmental programming}

\subsubsection{Structural effects}

\section{a) The endocrine pancreas:}

The structure of the endocrine pancreas seems to be particularly susceptible to changes nutrition in fetal life. Fetal pancreata from rat dams fed a low (8\%) protein (LP) diet had increased islet apoptosis (Petrik et al., 1999), reduced $\beta$-cell proliferation, decreased pancreatic islet size and diminished islet vascularisation (Snoeck et al., 1990) compared to $20 \%$ casein protein-fed (control) offspring. In old age (15 months), these offspring had increased markers of fibrosis compared to controls (Tarry-Adkins et al., 2010) Common aberrations in pancreatic structure is also apparent in models of maternal caloric restriction (50\%) whereby age-related loss of $\beta$-cell mass are observed in offspring of food restricted mothers (Garafano et al., 1999), and when these offspring were challenged with 
streptozotocin, $\beta$-cell regeneration was impaired (Garafano et al., 2000). Intrauterine placental ligation also has a deleterious effect on structure of the endocrine pancreas, with an age-dependent loss of relative $\beta$-cell mass (Simmons et al., 2001).

\section{b) The kidney:}

Nephron number and size are also commonly affected by models of suboptimal maternal nutrition. Severe maternal protein restriction using a $6 \%$ protein diet, leads to permanent reductions in nephron number in rat offspring (Merlet-Benichou et al., 1994), whereas milder maternal protein restriction (9\% protein diet, supplemented with methionine) caused reduced glomeruli number and hypertension in rat offspring (Langley-Evans et al., 1999). Both $6 \%$ and $9 \%$ maternal protein restriction has also been associated with increased apoptosis of renal mesenchymal cells at the start of renal development in the rat offspring (Welham et al., 2002). A rat model of $8 \%$ maternal protein restriction also resulted in reduced nephron number, glomerular enlargement, suppression of the renin-angiotensin system and hypertension in the offspring (Woods et al., 2001). A model of rat placental insufficiency has also shown nephron number deficits (Moritz et al., 2009) and a rat model of maternal iron restriction demonstrated reduced nephron number in 3 and 16 month old rat offspring (Lisle et al., 2003). All of these models may lead to age-associated kidney disease in later life.

\subsubsection{Epigenetics}

The concept that the environment to which a mother or father is exposed can influence health in not only their own offspring, but in future generations has brought about many studies focussing upon epigenetic mechanisms. Epigenetics are gene expression regulating mechanisms which are independent of genomic DNA sequence, and can involve persistent changes in chromatin conformation, such as DNA methylation and histone modifications and microRNAs (miRNAs). Various models of developmental programming 
have investigated epigenetic mechanisms in order to explain how a suboptimal maternal environment is capable of inducing effects on future generations.

Adults exposed to famine in-utero had reduced methylation of the IGF-2 DMR (Heijmans et al., 2008) and differential methylation of 15 loci implicated in growth and development compared to individuals not exposed to famine (Tobi et al., 2009). In animal models, offspring of rat dams with placental insufficiency had decreased $\mathrm{CpG}$ methylation of the cellular senescence marker $p 53$ and a parallel increase in p53 expression in the kidney (Pham et al., 2003) as well as genome-wide DNA hypomethylation and increased histone acetylation in liver (MacLennan et al., 2004) and progressively epigenetically silenced $P d x 1$ (via histone deacetylation) in pancreatic islets (Park et al., 2008). Administration of Exendin4 (a glucogon-like peptide-1 analogue) increased $P d x l$ levels in pancreatic islets of these offspring, via up-regulation of histone acetylation activity (Pinney et al., 2011). In a primate model of maternal obesity, hyperacetylation of the histone marks H3K14, H3K9 and H3K was observed in offspring, which was associated with depleted levels of histone deacetylase 1 (HDAC1), however this was not associated with gene repression, (Aagaard-Tillery et al., 2008). In mice, a maternal high-fat diet caused epigenetic alterations in Adiponectin and Leptin genes, which were detected through 3 generations (Masuyama et al., 2015). Cardiac levels of miR-133 were also elevated in mouse offspring of maternal obesity, which may be associated with the cardiac hypertrophy seen in these offspring (Blackmore et al., 2014). A rat model of maternal protein restriction has shown that Hnf4a (a transcription factor implicated in T2D), is epigenetically regulated by maternal diet and ageing in rat islets and that ageing leads to progressive epigenetic silencing of the entire Hnf4a locus in islets (Sandovichi et al., 2011). Adipose tissue from this model was also associated with increased miR-483-3p which regulates translation of growth differentiation factor-3 (Gdf3). This was also observed in adipose tissue of low birth weight young men (Ferland-MCollough et al., 

rat offspring, which was also observed in skeletal muscle of low birth weight diabetic monozygotic twins (Bork-Jensen et al., 2015). DNA methylation of Ppara and glucocorticoid receptor $(G r)$ genes was also reduced and gene expression increased in offspring of proteinrestricted mothers compared to controls. These epigenetic changes were prevented by folate supplementation (a known methyl donor, important in DNA methylation), (Lillycrop et al., 2005). Taken together, strong evidence exists to support the existence of epigenetic modifications in models of suboptimal maternal environments, which may be an important driver in transgenerational transmission of phenotype.

\subsubsection{Cellular ageing}

\section{Telomere length and Cellular Senescence:}

Telomeres are non-coding sequences at the ends of chromosomes, consisting of a variable number of tandem repeats of DNA (TTAGGG)n. In normal somatic cells (without telomerase), telomeres shorten with every cell division. When telomeres reach a critical length, they become dysfunctional and undergo a conformational change, resembling doublestranded breaks. This causes the cells to reach irreversible replicative senescence or apoptosis via up-regulation of senescence proteins $\mathrm{p} 53, \mathrm{p} 21$ and $\mathrm{p} 16^{\mathrm{INK}}$ and the apoptosis cascade (Harley et al., 1990). Consequently, many researchers consider that telomeres are associated with cellular ageing and replicative senescence (Harley et al., 1990, Bernodotte et al., 2016) and others have suggested that telomere length may be related to lifespan (Heidinger et al., 2012, Haussmann et al., 2003, Fairlie et al., 2016), however it needs to be noted that some researchers suggest telomere length is not a reliable proxy for biological ageing or lifespan (Bischoff et al, 2006, Mather et al., 2010). Previously, using a well-established Southern blotting based methodology, we have demonstrated accelerated telomere shortening in the aorta (Tarry-Adkins et al., 2008), heart (Tarry-Adkins et al., 2013), female reproductive tract 
381 (Aiken et al., 2013) and pancreatic islets (which was also associated with increased markers

382 of cellular senescence; p21 and p16 ${ }^{\mathrm{NK}}$ ) (Tarry-Adkins et al., 2009) of rat offspring whose mothers were protein-restricted and who then underwent accelerated postnatal growth (recuperated), suggesting that these offspring have an accelerated ageing phenotype which may contribute to their shortened lifespan. Conversely, a model of protein restriction during lactation, which causes slower postnatal growth showed fewer short aortic telomeres, reduced DNA damage and oxidative stress (Tarry-Adkins et al., 2008). Moreover, ovarian telomere length was also shortened in granddaughters of recuperated rat dams, showing that effects can be passed through more than one generation (Aiken et al., 2015).

\section{Oxidative stress:}

'The Harman free radical theory of ageing' postulates that oxidative stress is a major driver of accelerated cellular and whole body ageing, however most of the studies that support this hypothesis are associative and do not support a key and independent role of oxidative stress in modulating mammalian ageing. However, it cannot be disputed that high levels of oxidative stress is certainly deleterious to the cell. In particular, the mitochondria is known to be vulnerable to oxidative stress as it is the principle source of intracellular ROS leading to mitochondrial (mt)DNA mutations. These have been widely reported by be involved in the normal ageing process, however it still remains unclear the role mitochondrial dysfunction plays in longevity (Wang and Hekimi., 2015). Under pathophysiological conditions, ROS are over-produced by mitochondrial electron-transport chain (ETC) uncoupling, activation of the xanthine-oxidoreductase system or excessive stimulation of $\mathrm{NAD}(\mathrm{P}) \mathrm{H}$ which can overwhelm endogenous antioxidant defence mechanisms. When this occurs, ROS damages cellular macromolecules including DNA, lipids and proteins. This damage can accelerate telomere shortening in particular as the guanine-rich telomeric sequences are predominantly susceptible to oxidative stress (Kawanishi et al., 2004). 
406 Oxidative stress is a common factor in many models of developmental programming (Table

407 1). In a model of maternal protein restriction, combined with rapid postnatal growth,

408

409

410

411

412

413

414

415

416

417

418

419

420

421

422

423

424 increased indices of ROS, (including increased lipid peroxidation, protein nitrotyrosination and altered antioxidant defence capacity) was observed in the heart (Tarry-Adkins et al., 2013) and aorta (Tarry-Adkins et al., 2008) of male rats and in ovarian tissue of 'programmed' offspring (Aiken et al., 2013) In each case, these were associated with telomere shortening. Enhanced levels of oxidative stress (as evidenced by a decreased superoxide dismutase activity and increased superoxide anion concentrations) have also been implicated in a rat model of caloric restriction (50\%) in both male (Franco et al, 2002) and female offspring (Franco et al., 2007). Mitochondrial dysfunction in particular has been common in several models of 'developmental programming': Rat offspring from placental insufficiency pregnancies have impaired oxidative phosphorlyation in both hepatic (Peterside et al., 2003) and skeletal muscle mitochondria (Selak et al., 2003), as well as progressive accumulation of ROS, increased mtDNA mutations and a decline in complex I and III ETC activities in pancreatic islets (Simmons et al., 2005). Mouse offspring of obese pregnancies also demonstrate hepatic oxidative stress and mitochondrial dysfunction (Alfaradhi et al., 2014) and rat offspring of a maternal 'junk food' diet also demonstrate increased oxidative stress and mitochondrial dysfunction (Bayol et al., 2010). Defects in components of the mitochondrial ETC have also been observed in the skeletal muscle of both rat (Shelley et al., 2009) and mouse (Latouche et al., 2014) models of maternal obesity.

\subsection{Intervention strategies}

It is apparent that over-production of ROS is a common underlying consequence of sub-optimal maternal nutrition; therefore some animal studies have focussed on the use of antioxidant therapies to attempt to reverse the deleterious phenotypes observed in models of developmental programming. These included the use of high concentrations of vitamins $\mathrm{A}, \mathrm{C}$, 
431 E and selenium to reduce adiposity and improve glucose tolerance in rat offspring, which 432 resulted from a maternal exposure to a high-fat diet (Sen et al., 2010). Prevention of vascular dysfunction and microvascular rarefaction in rat offspring in a model of maternal protein restriction was also induced by antenatal treatment with the antioxidant Lazaroid (Cambonie et al., 2007). In an ovine model of nutrient restriction, pregnant ewes that were supplemented $5 \mathrm{mg}$ of melatonin had increased umbilical artery blood flow (Shukla et al., 2014). These studies all show proof of principle that antioxidant therapy can reverse deleterious phenotypes of developmental programming, however the doses used are far higher than used clinically and these studies focus on maternal supplementation, where in practice, phenotypes of developmental programming are more likely to be apparent at the time of or just after delivery, therefore postnatal antioxidant supplementation needs to be addressed. Our laboratory has demonstrated that a postnatal supplementation of a clinically relevant dose of Coenzyme $\mathrm{Q}_{10}\left(\mathrm{CoQ}_{10}\right)$ (an endogenous antioxidant) prevented cardiac (Tarry-Adkins et al., 2013), and aortic (Tarry-Adkins et al., 2014) accelerated ageing phenotypes, prevented adipose tissue insulin signaling dysregulation and inflammation (Tarry-Adkins et al., 2015) and ameliorated hepatic fibrosis and oxidative stress (Tarry-Adkins et al., 2016) in a rat model of maternal protein restriction followed by accelerated postnatal growth. It needs to be noted however although antioxidant therapy seems to have had some success in ameliorating some factors associated with age-related disease, no studies to date have successfully increased lifespan in laboratory rodents or reduced cancer morbidity/mortality in human random controlled trials and this warrants further investigation.

\section{Conclusions}

The increased risk of development of age-associated disease, including CVD, T2D, NAFDL and obesity is strongly associated with growth in conditions of a suboptimal maternal milieu, both as a direct transmission to the $1^{\text {st }}$ generation and via transgenerational 
456 transmission. It is evident that several common mechanisms exist between models of 457 suboptimal nutrition, irrespective as to whether these models are based on maternal under458 nutrition or over-nutrition. Structural perturbations in tissue, epigenetic modifications and 459 accelerated ageing, usually involving generation of ROS are all common to these models, in 460 both animal models and epidemiological populations. Although studies have begun to 461 address methods of intervention to reverse or prevent deleterious programming phenotypes, 462 especially antioxidant intervention, more research is needed to tease out further mechanisms 463 underpinning the phenomenon of developmental programming to tailor interventions suitable 464 for use in human populations.

\section{Acknowledgments}

467 This work was supported by The British Heart Foundation [PG/09/037/27387, 468 FS/09/029/27902]; and The Medical Research Council [MC_UU_12012/4]. 
1. Aagaard-Tillery, K.M., Grove, K., Bishop, J., Ke, X., Fu, Q., McKnight, R.M., Lane, R.H.,

472 2008. Developmental origins of disease and determinants of chromatin structure: maternal 473 diet modifies the primate fetal genome. J. Mol. Endo.41, 91-102.

474 2. Aiken, C.E., Tarry-Adkins, J.L., Ozanne, S.E., 2013. Suboptimal nutrition in utero causes 475 DNA damage and accelerated aging of the female reproductive tract. FASEB J. 27, 3959476 3965.

3. Aiken, C.E., Tarry-Adkins, J.L., Ozanne, S.E., 2015. Transgenerational developmental 478 programming of ovarian reserve. Sci. Rep. 5, 16175.

4. Aiken, C.E., Tarry-Adkins, J.L., Penfold, N., Dearden, L., Ozanne, S.E., 2016. Decreased ovarian reserve, dysregulation of mitochondrial biogenesis, and increased lipid peroxidation in female mouse offspring exposed to an obesogenic maternal diet. FASEB J. [Epub ahead of print].

5. Alfaradhi, M.Z., Fernandez-Twinn, D.S., Martin-Gronert, M.S., Musial, B., Fowden, A., Ozanne, S.E., 2014. Oxidative stress and altered lipid homeostasis in the programming of offspring fatty liver by maternal obesity. Am. J. Physiol. Regul. Integr. Comp. Physiol. 307, R26-R34.

6. Alwazel, S.H., Harrath, A., Aljarallah, J.S., Abotalib, Z., Osmond, C., Al Omar, S.Y., Khaled, I., Barker, D.J., 2013. Intergenerational effects of in utero exposure to Ramadan in Tunisia. Am. J. Hum. Biol. 25, 341-343. 
8. Barker, D.J., Hales, C.N., Fall, C.H., Osmond, C., Phipps, K., Clark, P.M., 1993. Type 2 (non-insulin-dependent) diabetes mellitus, hypertension, and hyperlipidaemia (syndrome $\mathrm{X}$ ): relation to reduced fetal growth. Diabetologia 36, 62-67.

9. Barros, M.A., de Brito Alves, J.L., Noquiera, V.O., Wanderely, A.G., Costa-Silva, J.H., 2015. Maternal low-protein diet induces changes in the cardiovascular autonomic modulation in rat offspring Nutr. Metab. Cardiovasc. Dis. 25, 123-130.

10. Bayol, S.A., Simbi, BH., Fowkes, R.C., Stickland, N.C., 2010. A maternal 'junk food' diet in pregnancy and lactation promotes nonalcoholic fatty liver disease in rat offspring. Endocrinology. 151, 1451-1461.

11. Beard, J, 2007. Recent evidence from human and animal studies regarding iron status and infant development. J. Nutr. 137, 524S-530S.

12. Bernadotte, A., Miklehson, V.M., Spivak, I.M., 2016. Markers of cellular senescence: Telomere shortening as a marker of cellular senescence. Aging (Albany NY) 1, 3-11.

13. Bischoff, C., Petersen, H.C., Graakjaer, J., Andersen-Ranberg, K., Vaupel, J.W., Bohr, V.A., Kolvraa, S., Christensen, K. No association between telomere length and survival among the elderly and oldest old. Epidemiology 17, 190-194.

14. Black, M.J., Lim, K., Zimanyi, M.A., Sampson, A.K., Bubb, K.J., Flower, R.L., Parkinton, H.C., Tare, M., Denton, K.M., 2015. Accelerated age-related decline in renal and vascular function in female rats following early-life growth restriction. Am. J. Physiol. Regul. Interg. Comp. Physiol. 309, R1153-R1161.

15. Blackmore, H.L, Neo, Y, Fernandez-Twinn, D.S, Tarry-Adkins, J.L, Giussani, D.A, Ozanne, S.E., 2014. Maternal diet-induced obesity programmes cardiovascular dysfunction in 
adult male mouse offspring independent of current body weight. Endocrinology. 155, 39703980.

516

16. Blagosklonny, M.V., 2007. Paradoxes of aging. Cell Cycle. 6, 2997-3003.

517

17. Boney, C.M., Verma, A., Tucker, R., Vohr, B.R., 2005. Metabolic syndrome in 518 childhood: association with birth weight, maternal obesity and gestational diabetes mellitus. 519 Pediatrics 115, e290 - e296.

18. Bork-Jensen, J., Scheele, C., Christopherson, D.V., Nilsson, E., Friedrichsen, M., 521 Fernandez-Twinn, D.S., Grunnert, L.G., Litman, T., Holmstrom, K., Vind, B., Hojlund, K., Beck-Nielson, H., Wojtaszewski, J., Ozanne, S.E., 2015. Pedersen, B.K., Poulsen, P., Vaag, A. Glucose tolerance is associated with differential expression of microRNAs in skeletal muscle: results from studies in twins with and without type 2 diabetes. Diabetologia. 58, 363373.

526

19. Cambonie, G., Comte, B., Yzydorczyk, C., Ntimbane, T., Germaine, N., Le, N.L., Pladys, 527 P., Gauthier, C., Lahaie, I., Abran, D., Lavoie, J.C., Nuyt, A.M., 2007. Am. J. Physiol. Regul. Integr. Comp. Physiol. 292, R1236-R1245.

20. Carr, S.K., Chen, J.H., Cooper, W.N., Constancia. M., Yeo, G., Ozanne, S.E., 2014. 530 Maternal diet amplifies the aging trajectory of Cidea in male mice and leads to the 531 development of fatty liver. FASEB J. 28, 2191-2201.

532 21. Chen, J.H., Martin-Gronert, M.S., Tarry-Adkins, J.L., Ozanne, S.E., 2009. Maternal 533 protein restriction affects postnatal growth and the expression of key proteins involved in 534 lifespan regulation in mice. PLoS One. 4, e4950. 
22. Chen, J.H., Tarry-Adkins, J.L., Heppolette, C.A.A., Palmer, D.B., Ozanne, S.E., 2010. Early-life nutrition influences thymic growth in male mice that may be related to the regulation of longevity. Clin. Sci. 118, 429-438.

23. Cox, L.A., Nijland, M.J., Gilbert, J.S., Schlabritz-Loutsevitch, N.E., Hubbard, G.B., McDonald, T.J., Shade, R.E., Nathanielsz, P.W., 2006. Effect of 30 per cent maternal nutrient restriction from 0.16 to 0.5 gestation on fetal baboon kidney gene expression. J. Physiol. 572, $67-85$

24. Crowther, N.J., Cameron, N., Trusler, J., Gray, I.P., 1998. Association between poor glucose tolerance and rapid postnatal weight gain in seven-year-old children. Diabetologia. $10,1163-1167$.

25. Dallschaft, N.S., Alexandre-Gouabau, M.C., Gardner, D.S., Antignac, J.P., Keisler, D.H., Budge, H., Symonds, M.E., Sebert, S.P., 2015. Effect of pre-and postnatal growth and postweaning activity on glucose metabolism in the offspring. J. Endocrinol. 224, 171-182.

26. Daraki, V., Georgiou, V., Papavasiliou, S., Chalkiadaki, G., Karahaliou, M., Koinaki, S., Sarri, K., Vassilaki, M., Kogevinas, M., Chatzi, L., 2015. Metabolic profile in early pregnancy is associated with offspring adiposity at 4 years of age: the Rhea pregnancy cohort Crete, Greece. PLoS One. 10, e0126327.

27. De Bruin, J.P., Dorland, M., Bruinse, H.W., Spleit, W., Nikkels, P.G., Te Velde, E.R., 1998. Fetal growth retardation as a cause of impaired ovarian development. Early Hum. Dev. 51, 39-46.

28. Djelanik, A.A.A.M.J., Kunst, A.E., van der Waal, M.F., Smit, H.A., Vrijkotte, T.G.M., 2011. Contribution of overweight and obesity to the occurrence of adverse pregnancy 
outcomes in a multi-ethic cohort: population attributive fractions for Amsterdam. 558 Epidemiology 119, 283-290.

559

560

561

562

563

564

565

566

567

568

569

570

571

572

573

574

575

576

577

578

579

29. de Rooij, S.R., van Pelt, A.M., Ozanne, S.E., Korver, C.M., van Daalen, S.K., Painter, R.C., Schwab, M., Viegas, M.H., Roseboom, T.J., 2015. Prenatal undernutrition and leukocyte telomere length in late adulthood: the Dutch famine birth cohort. Am. J. Clin. Nutr. $102,655-660$.

30. Elias, S.G., van Noord, P.A., Peters, P.H., den Tonkelaar, I., Grobbee, D.E., 2003. Caloric restriction reduces age at menopause: the effect of the 1944-1945 Dutch famine. Menopause. $10,399-405$.

31. Erikkson, J.G., Forsen, T., Tuomilehto, J., Winter, P.D., Osmond, C., Barker, D.J.P., 2001. Catch-up growth in childhood and death from coronary heart disease: longitudinal study. B.M.J. 318, 427-431.

32. Faienza, M.F., Brunetti, G., Ventura, A., D’Aniello, M., Pepe, T., Giordano, P., Monteduro, M., Cavallo, P., 2013. Nonalcoholic fatty liver disease in prepubertal children born small for gestational age: influence of rapid catch up growth. Horm. Res. Paediatr. 79, 103-109.

33. Fairlie, J., Holland, R., Pilkington, Pemberton, J.G., Harrington, L., Nussey, D.H., 2016. Lifelong leukocyte telomere dynamics and survival in a free-living mammal. Aging Cell 15, 140-148.

34. Ferland-McCollough, D., Fernandez-Twinn, D.S., Cannell, I.G., David, H., Warner, M., Vaag, A.A., Bork-Jensen, J., Brons, C., Gant, T.W., Willis, A.E., Siddle, K., Bushell, M., Ozanne, S.E., 2012. Programming of adipose tissue miR-483-3p and GDF-3 expression by maternal diet in type 2 diabetes. Cell Death Differ. 44, 1-10. 
580

581

582

583

584

585

586

587

588

589

590

591

592

593

594

595

596

597

598

599

600

601

35. Fernandez-Twinn, D.S., Blackmore, H.L., Siggens, L., Giussani, D.A., Cross, C.M., Foo, R., Ozanne, S.E, 2012. The programming of cardiac hypertrophy in the offspring by maternal obesity is associated with hyperinsulinemia, AKT, ERK, and mTOR activation. Endocrinology 153, 5961-5971.

36. Fewtrell, M.S., Morley, R., Abbott, R.A., Singhal, A., Stephenson, T., MacFadyen, U.M., Clements, H., Lucas, A., 2001. Catch-up growth in small for gestational-age infants: a randomized trial. Am. J. Clin. Nutr. 74, 516-523.

37. Fontana, L., Partridge, L, Longo, VD., 2010. Extending healthy life-span - from yeast to humans. Science 328, 321-326.

38. Franco, Mdo, C., Arruda, R.M., Fortes, Z.B., de Olivera, S.F., Carvalho, M.H., Tostes, R.C., Nigro, D., 2002. Severe nutrient restriction in pregnant rats aggravates hypertension, altered vascular reactivity, and renal development in spontaneously hypertensive rat offspring. J. Cardiovasc. Pharmocol. 39, 369-377.

39. Franco, Mdo C., Dantas, A.P., Akamine, E.H., Kawamoto, E.M., Fortes, Z.B., Scavone, C., Tostes, R.C., Carvalho, M.H., Nigro, D., 2002. Enhanced oxidative stress as a potential mechanism underlying the programming of hypertension in utero. J. Cardiovasc. Pharmocol. 40, 501-509.

40. Franco, MC., Akamine, E.H., Reboucas, N., Carvalho, M.H., Tostes, R.C., Nigro, D., Fortes, Z.B., 2007. Long-term effects of intrauterine malnutrition on vascular function in female offspring: implications of oxidative stress. Life Sci. 80, 709-715.

41. Gaillard, R., 2015. Maternal obesity during pregnancy and cardiovascular disease and development in later life. Eur. J. Epidemiol. 30, 1141-1152. 
602

603

604

605

606

607

608

609

610

611

612

613

614

615

616

617

618

619

620

621

622

42. Gambling, L., Charina, Z., Hannah, L., Antipatis, C., Lea, R.G., McCardle, H.J., 2002.

Effect of iron deficiency in placental cytokine expression and fetal growth in the pregnant rat. Biol. Reprod. 66, 516-523.

43. Garafano, A., Czernichow, P., Breant, B., 1999. Effect of ageing of beta-cell mass and function in rats malnourished during the perinatal period. Diabetologia. 42, 711-718.

44. Garafano, A., Czernichow, P., Breant, B., 2000. Impaired $\beta$-cell regeneration in perinatally manourished rats: a study with STZ. FASEB J. 14, 2611-2617.

45. Godfrey, K.M., Redman, C.W., Barker, D.J., Osmond, C., 1991. The effect of maternal anaemia and iron deficiency on the ratio of fetal weight to placental weight. Br. J. Obestet. Gynaecol. 98, 886-891.

46. Grunnet, L., Vielworth, S., Vaag A., Poulsen, P., 2007. Birth weight is nongenetically associated with glucose intolerance in elderly twins, independent of adult obesity. J. Intern. Med. 262, 96-103.

47. Guzman, C., Garcia-Becerra, R., Aguilar-Medina, M.A., Mendez, I., Merchant-Larios, H., Zambrano, E., 2014. Maternal protein restriction during pregnancy and/or lacatation negatively affects follicular ovarian development and steroidogenesis in the prepubertal rat. Arch. Med. Res. 45, 294-300.

48. Hales, C.N., Barker, D.J.P., 2001. The thrifty phenotype hypothesis. Br. Med. Bull. 60, 549. Hales, C.N., Barker, D.J.P., Clark, P.M.S., Cox, L.J., Fall, C., Osmond, C., Winter, P.D., 1991. Fetal and infant growth and impaired glucose tolerance at aged 64. B.M.J. 303, 10191022. 
623 50. Hales, C.N., Barker, D.J., 1992. Type-2 (non-insulin-dependent) diabetes mellitus: the 624 thrifty phenotype hypothesis. Diabetologia 35, 595-601.

625 51. Hardikar, A.A., Satoor, S.N., Karandikar, M.S., Joglekar, M.V., Puranik, A.S., Wong, W., 626 Kumar, S., Limaye, A., Bhat, D.S, Januszewski, A.S., Umrani, M.R., Ranjan, A.K., Apte, K., 627 Yajnik, P., Bhonde, R.R., Galande, S., Keech, A.C., Jenkins, A.J., Yajnik, C.S., 2015. 628 Multigenerational undernutrition increases susceptibility to obesity and diabetes that is not 629 reversed after dietary recuperation. Cell. Metab. 22, 1-8.

630

52. Harley, C.B., Fuchter, A.B., Greider, C.W., 1990. Telomeres shorten during ageing of 631 fibroblasts. Nature. 345, 448-460.

632

53. Haussmann, M.F., Winkler, D.W., O’Reilly, K.M., Huntington, C.E., Nisbet, I.C., Vleck, 633 C.M., 2003. Telomeres shorten more slowly in long-lived birds and mammals than in short634 lived ones. Proc. Biol. Soc. 270, 1387-1392.

635

54. Heidinger, B.J., Blount, J.D., Boner, W., Griffiths, K., Metcalfe, N.B., Monaghan, P., 636 2012. Telomere length in early life predicts lifespan. Proc. Natl. Acad. Sci. USA. 109, 1743637 1748.

55. Heijmans, B.T., Tobi, E.W., Stein, A.D., Putter, H., Blauw, G.J., Susser, E.S., Slagbloom, P.E., Lumey, L.H., 2008. Persistent epigenetic differences associated with prenatal exposure 640 to famine in humans. Proc. Natl. Acad. Sci. USA 105, 17046-17049.

56. Heppolette, C.A., Chen, J.H., Carr, S.K., Palmer, D.B., Ozanne, S.E., 2016. The effect of aging and maternal protein restriction during lactation on thymic involution and peripheral immunosenescence in adult mice. Oncotarget. [Epub ahead of print]. 
644

645

646

647

648

649

650

651

652

653

654

655

656

657

658

659

660

661

662

663

664

57. Jennings, B.J., Ozanne, S.E., Dorling, M.W., Hales, C.N., 1999. Early growth determines longevity in male rats and may be related to telomere shortening in the kidney. FEBS Lett. $448,4-8$.

58. Kawanishi, S., Oikawa, S., 2004. Mechanism of telomere shortening by oxidative stress. Ann. N. Y. Acad. Sci. 1019, 278- 284.

59. Kwon, D.H., Kang, W., Nam, Y.S., Lee, M.S., Lee, I.Y., Kim, H.J., Rajaseker, P., Lee, J.H., Bik, M., 2012. Dietary protein restriction leads to steatohepatitis and alters leptin/signal transducers and activators of transcription 3 signaling in lactating rats. J. Nutr. Biochem. 23, 791-799.

60. Langley-Evans, S.C., Welham, S.J.M., Jackson, A.A., 1999. Fetal exposure to a maternal low protein diet impairs nephrogenesis and promotes hypertension in the rat. Life Sci. 64, 965-974.

61. Latouche, C., Heywood, S.E., Henry, S.L., Ziemann, M., Lazarus, R., El-Osta, A., Armitage, J.A., Kingwell, B.A., 2014. Maternal overnutrition programs changes in the expression of skeletal muscle genes that are associated with insulin resistance and defects of oxidative phosphorylation in adult male rat offspring. J. Nutr. 144, 237-244.

62. Law, C.M., Shiell, A.W., Newsome, C.A., Syddall, H.E., Shinebourne, E.A., Fayers, P.M., Martyn, C.N., de Swiet, M., 2002. Fetal, infant and childhood growth and adult blood pressure: a longitudinal study from birth to 22 years of age. Circulation. 105, 1088-1092.

63. LeBourg, E., 2009. Hormesis, aging and longevity. Biochim. Biophys. Acta. 1790, 10301039. 
64. Lewis, R.M., Petry, C.J., Ozanne, S.E., Hales, C.N., 2001. Effects of maternal iron restriction in the rat on blood pressure, glucose tolerance and serum lipids in the 3-month-old offspring. Metabolism. 50, 562-570.

65. Lisle, S.J., Lewis, R.M., Petry, C.J., Ozanne, S.E., Hales, C.N., Forhead, A.J., 2003. Effect of maternal iron restriction during pregnancy on renal morphology in the adult rat offspring. Br. J. Nutr. 90, 33-39.

66. Lillycrop, K.A., Phillips, E.S., Jackson, A.A., Hanson, M.A., Burdge, G.C., 2005. Dietary protein restriction of pregnant rats induces and folic acid supplementation prevents epigenetic modification of hepatic gene expression in the offspring. J. Nutr. 135, 1382-1386.

67. MacLennan, N.K., James, S.J., Melnk, S., Piroozi, A., Jernigan, S., Hsu, J.L., Janke, S.M., Pham, T.D., Lane, R.H., 2004. Uteroplacental insufficiency alters DNA methylation, one carbon metabolism, and histone acetylation in IUGR rats. Physiol. Genomics 18, 43-50.

68. Martin, R.M., Gunnell, D., Davey-Smith, G., 2005. Breast-feeding in infancy and bloodpressure in later life; systemic review and meta-analysis. Am. J. Epidemiol. 161, 15-26.

69. Masuyama, H., Mitsui, T., Nobumoto, E., Hiramatsu, Y., 2015. The effects of high-fat diet exposure on the obesogenic and diabetogenic traits through epigenetic changes in adiponectin and leptin gene expression for multiple generations in female mice. Endocrinology 156, 2482-2491.

70. Mather, K.A., Jorm, A.F., Milburn, P.J., Tan, X., Easteal, S., Christensen, H., 2010. No associations between telomere length and age-sensitive indicators of physical function in mid and later life. J. Gerontol. A. Biol. Sci. Med. Sci. 65, 792-799. 
686

687

688

689

690

691

692

693

694

695

696

697

698

699

700

701

702

703

704

705

706

707

708

71. Mazzuca, M.Q., Wlodek, M.E., Dragomir, N.M., Parkington, H.C., Tare, M., 2010.

Uteroplacental insufficiency programs regional vascular dysfunction and alters arterial stiffness in female offspring. J. Physiol. 588, 1997-2010.

72. McCance, D.R., Pettitt, D.J., Hanson, R.L., Jacobsson, L.T., Knowler, W.C., Bennett, P.H., 1994. Birth weight and non-insulin dependent diabetes: thrifty genotype, thrifty phenotype, or surviving baby phenotype? B.M.J. 308, 942-945.

73. McCurdy, C.E., Bishop, J.M., Williams, S.M., Grayson, B.E., Smith, M.S., Friedman, J.E., Grove, K.L., 2009. Maternal high-fat diet triggers lipotoxicity in the fetal livers of nonhuman primates. J Clin Invest. 119, 323-335.

74. Merlet-Benichou, C., Gilbert, T., Muffat-Jolie, M., Lelievre-Pegorier, M., Leroy, B., 1994. Intrauterine growth retardation leads to a permanent nephron deficit in the rat. Pediatr. Nephrol. 8, 175-180.

75. Michan, S. 2014. Caloric restriction and $\mathrm{NAD}^{+}$.sirtuin counteract the hallmarks of aging. Front Biosci (Landmark Ed) 19, 1300-1319.

76. Moritz, K.M., Mazzuca, M.Q., Siebel, A.L., Milbus, A., Arena, D., Tare, M., Owens, J.A., Wlodek, M.A., 2009. Uteroplacental insufficiency causes a nephron deficit, modest renal insufficiency but no hypertension with ageing in female rats. J. Physiol. 587, 26352646.

77. Oben, J.A., Mouralidarane, A., Samuelsson, A.M., Matthews, P.J., Morgan, M.L., McKee, C., Soeda, J., Fernandez-Twinn, D.S., Martin-Gronert, M.S., Ozanne, S.E., Sigala, B., Novelli, M., Poston, L., Taylor, P.D., 2010. Maternal obesity during pregnancy and lactation programs the development of offspring non-alcoholic fatty liver disease in mice. J. Hepatol. 52, 913-920. 
78. Ong, K.K., Petry, C.J., Emmett, P.M., Sandhu, M.S., Kiess, W., Hales, C.N., Ness, A.R., Dunger, D.B., 2004. Insulin sensitivity and secretion in normal children related to size at birth, postnatal growth and plasma-like growth factor-1 levels. Diabetologia. 6, 1064-1070.

79. Owen, C.G., Whincup, P.H., Odoki, K., Gilg, J.A., Cook, D.G., 2002. Infant feeding and blood cholesterol: a study in adolescents and a systematic review. Pediatrics. 110, 597-608. 80. Ozanne, S.E., Hales, C.N., 2004. Lifespan: catch-up growth and obesity in male mice. Nature. 427, 411-412

81. Ozanne, S.E., Jensen, C.B., Tingey, K.J., Storgaard, H., Madsbad, S., Vaag, A., 2005. Low birth weight is associated with specific changes in muscle insulin-signalling protein expression. Diabetologia. 48, 547-552.

82. Ozanne, S.E., Jensen, C.B., Tingey, K.J., Martin-Gronert, M.S., Grunnet, L., Brons, C., Storgaard, H., Vaag, A.A., 2006. Decreased protein levels of key insulin signalling molecules in adipose tissue from young men with a low birthweight: potential link to increased diabetes? Diabetologia. 49, 2993-2999.

83. Painter, R.C., Roseboom, T.J., van Montfrans, G.A., Bossuyt, P.M.M., Krediet, R.T., Osmond, C., Barker, D.J., Bleker, O.P., 2005. Microalbuminurea in adults after prenatal exposure to the Dutch famine. J. Am. Soc. Nephr. 1, 189-194.

84. Painter, R.C., Osmond, C., Gluckman, P., Hanson, M., Phillips, D.I.W., Roseboom, T.J., 2008. Transgenerational effects of prenatal exposure to the Dutch famine on neonatal adiposity and health in later life. B.J.O.G. 115, 1243-1249.

85. Park, J.H., Stoffers, D.A., Nicholls, R.D., Simmons, R.A., 2008. Development of type 2 diabetes following intrauterine growth retardation in rats is associated with progressive epigenetic silencing of $P d x$ l. J.C.I. 118, 2316-2324. 
86. Peterside, I.E., Selak, M.A., Simmons, R.A., 2003. Impaired oxidative phosphorylation in hepatic mitochondria in growth-retarded rats. Am. J. Physiol. Endocrinol. Metab. 285, E1258-E1266.

87. Petrik, J., Reusens, B., Arany, E., Remacl, C., Coelho, C., Hoet, J. J., Hill, D. J., 1999. A low protein diet alters the balance of islet cell replication and apoptosis in the fetal and neonatal rat and is associated with a reduced pancreatic expression of insulin-like growth factor-II. Endocrinology 140, 4861-4873.

88. Petry, C.J., Dorling, M.W., Pawlak, D.B., Ozanne, S.E., Hales, C.N., 2001 Diabetes in old male offspring of rat dams fed a reduced protein diet. Int. J. Exp. Diabetes Res. 2, 139143.

89. Pham, T., MacLellan, N.K., Chiu, C.T., Laksana, G.S., Hsu, J.L., Lane, R.H., 2003. Uteroplacental insufficiency increases apoptosis and alters p53 gene methylation in the fullterm rat kidney. Am. J. Physiol. Regul. Integr. Comp. Physiol. 285, R962-R970.

90. Pinney, S.E., Jaeckle-Santos, L.J., Han, Y., Stoffers, D.A., Simmons, R.A., 2011. Exendin-4 increases histone acetylase activity and reverses epigenetic modifications that silence Pdx1 in the intrauterine growth retarded rat. Diabetologia 54, 2606-2614.

91. Poulsen, P., Vaag, A.A., Kyvik, K.O., Moller Jensen, D., Beck-Nielsen, H., 1997. Low birth weight is associated with NIDDM in discordant monozygotic and dizygotic twin pairs. Diabetologia. 40, 439-446.

92. Poulsen, P., Levin, K., Beck-Nielsen, H., Vaag, A., 2002. Age-dependent impact of zygosity and birth weight on insulin secretion and in twins, Diabetologia. 45, 1649-1657. 
753

754

755

756

757

758

759

760

761

762

763

764

765

766

767

768

769

770

771

772

773

774

775

93. Poulsen, P., Vaag, A., 2006. The intrauterine environment as reflected by birth size and twin and zygosity status influences insulin action and intracellular glucose metabolism in an age-or time-dependent manner. Diabetes. 55, 1819-1825.

94. Ravelli, A.C., Van der Meulen, J.H., Michels, R.P., Osmond, C., Barker, D.J., Hales, C.N., Bleker, O.P., 1998. Glucose tolerance in adults after prenatal exposure to famine. Lancet. 351, 173-177.

95. Ravelli, A.C.J., Van der Meulen, J.H.P., Osmond, C., Barker, D.J.P., Bleker, O.P., 2000. Infant feeding and adult glucose tolerance, lipid profile, blood pressure and obesity. Arch. Dis. Child. 82, 248-252.

96. Reynolds, R.M, Allan, K.M., Raja, E.A., Bhattacharya, S., McNeill, G., Hannaford, P.C., Sarwar, N., Lee, A.J., Bhattacharya, S., Norman, J.E., 2013. Maternal obesity during pregnancy and premature mortality from cardiovascular disease event in adult offspring: follow-up of 1323275 person years. B.M.J. 347, f4539.

97. Roseboom, T., de Roijj, S., Painter, R., 2006. The Dutch famine and its long-term consequences for adult health. Early Human Dev. 82, 485-491.

98. Samuelsson, A.M., Matthews, P.A., Argenton, M., Christie, M.R., McConnell, J.M., Jansen, E.H.J.M., Peirsma, A.H., Ozanne, S.E., Fernandez-Twinn, D., Remacle, C., Rowlerson, A., Poston, L., Taylor, P.D., 2008. Diet-induced obesity in female mice leads to offspring hyperphagia, adiposity, hypertension, and insulin resistance: a novel murine model of developmental programming. Hypertension 51, 383-392.

99. Sandovici, I., Smith, N.S., Dekker Nitert, M., Ackers-Johnson, M., Uribe-Lewis, S., Ito, Y., Jones, R.H., Marquez, V.E., Cairns, W., Tadavyon, M., O;Neill, L.P., Murrell, A., Ling, C., Constancia, M., Ozanne, S.E, 2011. Maternal diet and aging alter the epigenetic control of 
a promoter-enhancer interaction at the $H n f \alpha$ gene in rat pancreatic islets. P.N.A.S. 108, 54495454.

100. Selak, M.A., Storey, B.T., Peterside, I., Simmons, R.A., 2003. Impaired oxidative phosphorylation in skeletal muscle of intrauterine growth-retarded rats. Am. J. Physiol. Endocrinol. Metab. 285, E130-E137.

101. Sen, S., Simmons, R.A., 2010. Maternal antioxidant supplementation prevents adiposity in Western diet fed rats. Diabetes. 59, 3058-3065.

102. Shelley, P., Martin-Gronert, M.S., Rowlerson, A., Poston, L., Heales, S.J., Hargreaves, I.P., McConnell, J.M., Ozanne, S.E., Fernandez-Twinn, D.S., 2009. Altered skeletal muscle insulin signaling and mitochondrial complex II-III linked activity in adult offspring of obese mice. Am. J. Physiol. Integr. Comp. Physiol. 297, R675-R681. 2014. Effect of maternal nutrient restriction and melatonin supplementation from mid to late gestation on vascular reactivity of maternal and fetal placental arteries. Placenta 35, 461-466. 104. Simmons, R.A., Templeton, L.J., Gertz, S.J., 2001. Intrauterine growth retardation leads to development of type 2 diabetes in rats. Diabetes. 50, 2279-2286.

105. Simmons, R.A., Supontisky-Kroyter, I., Selak, M.A., 2005. Progressive decline of mitochondrial DNA mutations and decline in mitochondrial function lead to $\beta$-cell failure. J. Biol. Chem. 31, 28785-28791.

106. Slobada, D.M., Hart, R., Doherty, D.A., Pennell, C.E., Hickey, M., 2007. Age at menarche: Influences of prenatal and postnatal growth. J. Clin. Endocrinol. Metab. 92, 46-50. the fetal rat pancreas. Biol. Neonate. 50, 107-118. 
108. Steenweg-Graaff, J., Roza, S.J., Steegers, E.A., Hofman, A., Verlhurst, F.C., Jaddoe, V.W., Tiemeier, H., 2012. Maternal folate status in early pregnancy and child emotional and behavioral problems: the Generation R study. Am. J. Clin. Nutr. 95, 1413-1420.

109. Tain, Y.L., Hsu, C.N., Chan, J.Y., Huang, L.T., 2015. Renal transcriptome analysis of programmed hypertension induced by maternal nutritional insults. Int. J. Mol. Sci. 16, 1782617837.

110. Tarry-Adkins, J.L., Joles, J.A., Chen, J.H., Martin-Gronert, M.S., van der Giezen, D.M., Goldschmeding, R., Hales, C.N., Ozanne, S.E., 2007. Protein restriction in lactation confers nephroprotective effects in the male rat and is associated with increased antioxidant expression. Am. J. Physiol - Regul. Integr. Comp. Physiol. 293, R1259-R1266.

111. Tarry-Adkins, J.L., Martin-Gronert, M.S., Chen, J.H., Cripps, R.L., Ozanne, S.E., 2008. Maternal diet influences DNA damage, aortic telomere length, oxidative stress and antioxidant defense capacity in male rats. FASEB J. 22, 2037-2044.

112. Tarry-Adkins, J.L., Chen, J.H., Smith, N.S., Jones, R.H., Cherif, H., Ozanne, S.E., 2009. Poor maternal nutrition followed by accelerated postnatal growth leads to telomere shortening and increased markers of cellular senescence. FASEB J. 23, 1521-1528.

113. Tarry-Adkins, J.L., Chen, J.H., Jones, R.H., Smith, N.S., Ozanne, S.E., 2010. Poor maternal nutrition leads to alterations in oxidative stress, antioxidant defense capacity and markers of fibrosis in rat islets: potential underlying mechanisms for development of the diabetic phenotype in later life. FASEB J. 24, 2762-2771.

114. Tarry-Adkins, J.L., Blackmore, H.L., Martin-Gronert, M.S., Fernandez-Twinn, D.S., McConnell, J.M., Hargreaves, I.P., Giussani, D.A., Ozanne, S.E., 2013. Coenzyme Q ${ }_{10}$ 
prevents accelerated cardiac aging in a rat model of poor maternal nutrition and accelerated postnatal growth. Mol. Metab. 2, 480-490.

115. Tarry-Adkins, J.L., Fernandez-Twinn, D.S., Chen, J.H., Hargreaves, I.P., MartinGronert, M.S., McConnell, J.M., Ozanne, S.E., 2014. Nutritional programming of Coenzyme Q: potential for prevention and intervention? FASEB J. 28, 5398-5405.

116. Tarry-Adkins, J.L., Fernandez-Twinn, D.S., Madsen, R., Chen, J.H., Carpenter, A.M.M., Hargreaves, I.P.P., McConnell, J.M., Ozanne, S.E., 2015. Coenzyme $\mathrm{Q}_{10}$ prevents insulin signalling dysregulation and inflammation prior to development of insulin resistance in male offspring of a rat model of poor maternal nutrition and accelerated postnatal growth. Endocrinology. 156, 3528-3537.

117. Tarry-Adkins, J.L., Fernandez-Twinn, D.S., Hargreaves, I.P., Neergheen, V., Aiken, C.E., Martin-Gronert, M.S., McConnell, J.M., Ozanne, S.E., 2016. Coenzyme Q ${ }_{10}(\mathrm{CoQ})$ prevents hepatic fibrosis, inflammation and oxidative stress in a male rat model of poor maternal nutrition and accelerated postnatal growth. Am. J. Clin. Nutr. 103, 579-588.

118. Tobi, E.W., Lumey, L.H., Talens, R.P., Kremer, D., Putter, H., Stein, A.D., Slagbloom, P.E., Heijmans, B.T., 2009. DNA methylation differences after exposure to prenatal famine are common and timing and sex-specific. Hum. Mol. Genet. 18, 4046-4053.

119. Touwslager, R.N., Houben, A.J., Tan, F.E., Gielen, M., Zeegers, M.P., Stehouwer, C.D., Gerver, W.J., Westerterp, K.R., Wouters, L., Blanco, C.E., Zimmermann, L.J., Mulder, A.L., 2015. Growth and endothelial function in the first two years of life. J. Pediatr. 166, 666-67s1.

120. Tran, M., Young, M.E., Jeffries, A.J., Hryciw, D.H., Ward, M.M., Fletcher, E.L., Wlodek, M.E., Wadley, G.D., 2015. Uteroplacental insufficiency leads to hypertension but 
843

844

845

846

847

848

849

850

851

852

853

854

855

856

857

858

859

860

861

862

863

not glucose intolerance or impaired skeletal muscle biogenesis, in 12-month-old rats. Physiol. Rep. 3, e12556.

121. Veenendaal, M.V., Painter, R.C., de Rooij, S.R., Bossuyt, P.M., van der Post, J.A., Gluckman, P.D., Hanson, M.A., Roseboom, T.J., 2013. Transgenerational effects of prenatal exposure to the 1944-1945 Dutch famine. B.J.O.G. 120, 548-553.

122. Vickers, M.H., Reddy, S., Ikenasio, B.A., Breier, B.H., 2001. Dysregulation of the adipoinsular axis - a mechanism for the pathogenesis of hyperleptinemia and adipogenic diabetes induced by fetal programming. J. Endocrinol. 170, 323-332.

123. Vuguin, P., Raab, E., Liu, B., Barzilai, N., Simmons, R., 2004. Hepatic insulin resistance precedes the development of diabetes in a model of intrauterine growth restriction.

Diabetes 53, 2617-2622.

124. Wang, Y., Hekimi, S., 2015. Mitochondrial dysfunction and longevity: untangling the knot. Science 350, 1204-1207.

125. Welham, S.J., Wade, A., Woolfe, A.S., 2002. Protein restriction in pregnancy is associated with increased apoptosis of mesenchymal cells at the start of renal metanephrogenesis. Kidney Int. 61, 1231-1242.

126. Whitaker, RC., 2004. Predicting preschooler obesity at birth: the role of maternal obesity in early pregnancy. Pediatrics. 114, e29-e36.

127. Woods, L.L., Ingelfinger, J.R., Nyengaard, J.R., Rasch, R., 2001. Maternal protein restriction suppresses the new-born renin-angiotensin system and programs adult hypertension in the rat. Pediatr. Res. 49, 460-467. 
864 128. Zambrano, E., Rodriguez-Gonzalez, G.L., Guzman, C., Garcia-Becarra, R., Boeck, L., 865 Diaz, L., Menjivar, M., Larrae F., Nathanielsz, P.W., 2005. A maternal low protein during 866 pregnancy and lactation in the rat impairs male reproductive development. J. Physiol. 563, $867 \quad 275-284$. 